\title{
Chemoselective reactions of dimethyl carbonate catalysed by alkali metal exchanged faujasites: the case of indolyl carboxylic acids and indolyl- substituted alkyl carboxylic acids
}

\author{
Maurizio Selva, ${ }^{*}$ Pietro Tundo, Davide Brunelli and Alvise Perosa \\ Received 14th November 2006, Accepted 22nd January 2007 \\ First published as an Advance Article on the web 14th February 2007 \\ DOI: $10.1039 / \mathrm{b} 616656 \mathrm{c}$
}

At $160-180{ }^{\circ} \mathrm{C}$, in the presence of alkali metal exchanged faujasites (MX or MY; $\mathrm{M}=\mathrm{Li}, \mathrm{Na}, \mathrm{K}$ ), the reaction of dimethyl carbonate with indolyl-3-acetic, -3-propionic, and -3-butyric acids proceeds towards the formation of the corresponding methyl esters or carbamate esters which can be isolated in 93-99\% yields. The methylation of the indolyl-NH group is never observed. This high chemoselectivity is driven by the nature of the catalyst and the reaction temperature. In particular, among the six different zeolites used, the more basic MX faujasites show better performances in terms of both activity and selectivity than MY solids. A similar trend also holds for the reaction of dimethyl carbonate with indolyl-carboxylic acids, where MX compounds are still efficient catalysts for the formation of methyl esters. In this case, however, the overall reactivity/selectivity also reflects the relative positions of the $\mathrm{NH}$ and $\mathrm{CO}_{2} \mathrm{H}$ groups which may account for significant decarboxylation reactions observed for indolyl acids substituted at positions 2 and 3. This process is totally absent for indolyl-6-carboxylic acid.

\section{Introduction}

In the past two decades, the non-toxic dimethyl carbonate $\left(\mathrm{MeOCO}_{2} \mathrm{Me}, \mathrm{DMC}\right)$ has emerged as a green candidate for the replacement of highly noxious compounds such as phosgene and methyl halides/sulfate, in both methylation and methoxycarbonylation reactions. ${ }^{1}$ A number of homogeneous and heterogeneous catalysts have been reported for DMCmediated processes: $:^{1,2}$ among them, we recently observed that alkali metal exchanged faujasites offered unique possibilities to catalyze methylation and esterification reactions. Most relevant examples were in the class of ambident nucleophiles. In the presence of $\mathrm{NaY}$ faujasite, the reaction of dimethyl carbonate with amino-phenols, -benzyl alcohols, -benzoic acids, and -benzamides not only showed a very high mono$N$-methyl selectivity (up to $99 \%$ ), but it proceeded with complete chemoselectivity towards the amino group [Scheme 1, path (a)]. ${ }^{3}$ The other nucleophilic functionalities $\left(\mathrm{OH}, \mathrm{CO}_{2} \mathrm{H}, \mathrm{CH}_{2} \mathrm{OH}, \mathrm{CONH}_{2}\right)$ were fully preserved from alkylation and/or transesterification reactions.

Likewise, at a higher temperature of $165^{\circ} \mathrm{C}$, the $\mathrm{DMC} / \mathrm{NaY}$ system allowed the exclusive esterification of hydroxy-benzoic acids (ortho- and para-isomers), mandelic acid, and phenyllactic acid, without affecting aromatic and aliphatic $\mathrm{OH}$ substituents [Scheme 1, paths (b) and (c)]. ${ }^{4}$

All these processes were genuine green examples: they were truly catalytic, they did not require additional solvents (DMC served simultaneously as a reagent and solvent), and they released only $\mathrm{MeOH}$ and $\mathrm{CO}_{2}$ as co-products. Moreover,

Dipartimento di Scienze Ambientali dell'Università Ca' Foscari, and Consorzio Interuniversitario "La Chimica per l'Ambiente" (INCA), UdR di Venezia, Calle Larga S. Marta 2137, Venezia, 30123, Italy.

E-mail: selva@unive.it; Fax: +390412348 620; Tel: +39041 2348687 typical selectivities of reactions of Scheme 1 were in the range of $90-100 \%$ : in a single step, with no derivatization (protection/de-protection) sequences, the desired methylamines or methyl esters were isolated in $80-99 \%$ yields.

On the contrary, in the presence of basic catalysts (i.e. $\mathrm{K}_{2} \mathrm{CO}_{3}$ ), competitive reactions of $O$ - and bis $N, N$-methylation, $N$ - and $O$-methoxycarbonylation took place simultaneously.

These findings prompted us to face the problem of indolylsubstituted alkyl carboxylic acids and of indolyl carboxylic acids, which were both good models of ambident nucleophiles and examples of structural components of auxins and many pharmaceutical agents. ${ }^{5}$ In particular, we focused our

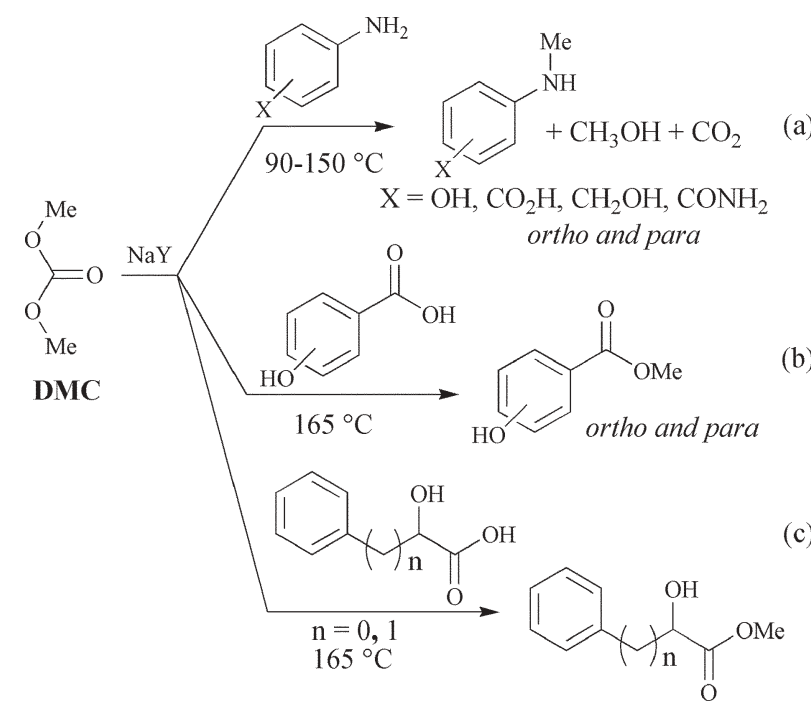

Scheme 1 Chemoselective reactions of DMC in the presence of $\mathrm{NaY}$ catalyst. 
<smiles>O=C(O)Cc1c[nH]c2ccccc12</smiles>

1a: $\mathrm{n}=0$

1b: $\mathrm{n}=1$

1c: $\mathrm{n}=2$

1d: $\mathrm{n}=3$

Scheme 2<smiles>O=C(O)Cc1c[nH]c2ccccc12</smiles>

$\mathrm{n}=1,2$

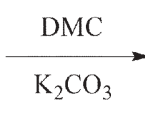<smiles>COC(=O)Cc1cn(C)c2ccccc12</smiles>

$\mathrm{Y}=65-95 \%$

Scheme 3

attention on indolyl-3-carboxylic, -acetic, -propionic, and -butyric acids (compounds 1a-d), and on indolyl-2-carboxylic, and -6-carboxylic acids (compounds 1e and 1f) (Scheme 2).

At $130{ }^{\circ} \mathrm{C}$, Jiang et al. already reported that reactions of DMC with acids $\mathbf{1 a}-\mathbf{d}$ were efficiently catalyzed by $\mathrm{K}_{2} \mathrm{CO}_{3},{ }^{6}$ however, chemoselectivity was elusive because competitive processes of esterification and $\mathrm{N}$-methylation occurred to comparable extents (Scheme 3).

In the case of 1a, it was observed that a decarboxylation process also took place to give $N$-methylindole in $45 \%$ yield.

We wish to report herein that at $150-180{ }^{\circ} \mathrm{C}$, the same reactions of acids $\mathbf{1 b} \mathbf{d}$ and $\mathbf{1 f}$, became highly selective when carried out over alkali metal exchanged faujasites, particularly of the X type: only methyl esters were obtained in substantially quantitative yields, without affecting the $\mathrm{NH}$ group. For longer reaction times, carbamate esters coming from simultaneous esterification and $N$-methoxycarbonylation of indolyl substrates were isolated in up to $99 \%$ yield. Under these conditions, acids 1a and 1e underwent both decarboxylation and esterification reactions, but the methylation of the indolyl-NH group was not appreciable. The outcome was primarily driven by the acido-basic properties of the zeolite catalysts.

\section{Results}

Six different faujasites, namely MY and MX ( $\mathrm{M}=\mathrm{Li}, \mathrm{Na}, \mathrm{K})$ were used as catalysts: four of them $(\mathrm{M}=\mathrm{Li}$ and $\mathrm{K})$, were prepared through conventional ionic exchange reactions, starting from two commercially available samples of zeolites ( $\mathrm{NaY}$ and $\mathrm{NaX}$, respectively) and $\mathrm{LiCl}$ or $\mathrm{KCl}$ as precursors. ${ }^{7}$ The main features of these catalysts are summarized in Table 1.

The reaction of DMC with indolyl-3-acetic acid 1b was initially investigated. In the presence of MX or MY catalysts, a solution of $\mathbf{1 b}$ in DMC $\left(4.5 \times 10^{-2} \mathrm{M}, 30 \mathrm{~mL}\right)$ was set to react at 160 and $180{ }^{\circ} \mathrm{C}$, in a stainless-steel autoclave $(90 \mathrm{~mL})$. Weight ratios $(Q) \mathrm{MX}: \mathbf{1 b}$ or $\mathrm{MY}: \mathbf{1 b}$ ranged from 1 to 0.05 , and different reaction times of $4-15 \mathrm{~h}$ were considered.
Table 1 Faujasite catalysts used in the reaction of DMC with acids 1a-c

\begin{tabular}{lcc}
\hline Starting zeolite $(\mathrm{Na}, \%)^{a}$ & Product & Ionic exchange (\%) \\
\hline NaX (7.5) & LiX & 71 \\
NaX (7.5) & KX & 92 \\
NaY (8) & LiY & 67 \\
NaY (8) & KY & 86 \\
${ }^{a}$ The Na content was evaluated through atomic absorption (AA). \\
${ }^{b}$ Percentage of ionic exchange (from NaX and NaY, respectively) \\
\multicolumn{2}{l}{ was evaluated by AA (K) and emission (Li). } \\
\hline
\end{tabular}<smiles>COC(=O)Cc1c[nH]c2ccccc12</smiles>

Scheme 4

After purification of reaction mixtures [flash-column chromatography (FCC): petroleum ether-diethyl ether, $2: 3 \mathrm{v} / \mathrm{v}]$, four products were isolated and identified by GC/MS and by NMR (Scheme 4). The results are reported in Table 2.

In the absence of catalysts, the acid $\mathbf{2} \mathbf{b}$ was recovered unreacted after $3 \mathrm{~h}$ at $180{ }^{\circ} \mathrm{C}$ (Table 2, entry 1). At the same temperature $\left(180{ }^{\circ} \mathrm{C}, 4 \mathrm{~h}, Q=1\right)$, reactions carried out over MY zeolites showed good conversions (68-75\%) but modest selectivities (entries 2-4): the methyl ester $\mathbf{2 b}$ was formed along with 3-methylindole (4b, 19-43\%). The latter plausibly originated from the decarboxylation of indolyl-3-acetic acid. ${ }^{8}$

Table 2 The reaction of DMC with $\mathbf{1 b}$ in the presence of different zeolites

\begin{tabular}{|c|c|c|c|c|c|c|c|c|c|}
\hline \multirow[b]{2}{*}{ Entry } & \multirow[b]{2}{*}{ Cat. } & \multirow{2}{*}{$\begin{array}{l}\text { Cat. : } \\
\text { substr. } \\
(Q)^{a}\end{array}$} & \multirow[b]{2}{*}{$t / \mathrm{h}$} & \multirow[b]{2}{*}{$T /{ }^{\circ} \mathrm{C}$} & \multirow{2}{*}{$\begin{array}{l}\text { Conv. } \\
(\%)^{b}\end{array}$} & \multicolumn{4}{|c|}{$\begin{array}{l}\text { Isolated product } \\
\text { yield }(\%)^{c}\end{array}$} \\
\hline & & & & & & $2 b$ & 3b & $4 b$ & $5 b$ \\
\hline 1 & None & & 3 & 180 & $<1$ & & & & \\
\hline 2 & $\mathrm{LiY}$ & 1 & 4 & 180 & 68 & 25 & & 43 & \\
\hline 3 & $\mathrm{NaY}$ & 1 & 4 & 180 & 75 & 52 & & 21 & \\
\hline 4 & KY & 1 & 4 & 180 & 72 & 50 & & 19 & \\
\hline 5 & $\mathrm{NaY}$ & 0.1 & 15 & 180 & 75 & 56 & & 16 & \\
\hline 6 & $\mathrm{NaY}$ & 0.5 & 9 & 180 & 80 & 55 & & 25 & \\
\hline 7 & $\mathrm{NaY}$ & 0.5 & 15 & 180 & 100 & & 61 & & 35 \\
\hline 8 & LiX & 1 & 4 & 180 & 95 & 87 & 10 & & \\
\hline 9 & $\mathrm{NaX}$ & 1 & 4 & 180 & $>99$ & & 97 & & \\
\hline 10 & KX & 1 & 4 & 180 & $>99$ & & 98 & & \\
\hline 11 & $\mathrm{NaX}$ & 1 & 3 & 160 & $>99$ & 95 & & & \\
\hline 12 & $\mathrm{NaX}$ & 0.1 & 9 & 160 & $>99$ & 93 & & & \\
\hline 13 & $\mathrm{NaX}$ & 0.05 & 9 & 160 & 46 & 44 & & & \\
\hline 14 & KX & 0.1 & 8 & 160 & $>99$ & 96 & & & \\
\hline \multicolumn{10}{|c|}{$\begin{array}{l}{ }^{a} \text { Weight ratio zeolite : } \mathbf{1 b}{ }^{b} \text { Based on the recovered starting reagen } \\
\mathbf{1 b}{ }^{c} \text { Yields of } \mathbf{2 b}-\mathbf{5 b} \text { were evaluated after purification by flash } \\
\text { column chromatography on silica gel (eluant: petroleum ether- } \\
\text { diethyl ether, } 2: 3 \mathrm{v} / \mathrm{v} \text { ). }\end{array}$} \\
\hline
\end{tabular}


In the presence of $\mathrm{NaY}$, a similar selectivity could be accomplished even by using lower $Q$ ratios $(\mathrm{NaY}: \mathbf{1 b}=0.1$ and $0.5 ; 4 \mathbf{b}: 16-25 \%$, entries 5 and 6 ). If the reaction was continued for a longer time $(15 \mathrm{~h}, Q=0.5)$, a quantitative conversion was reached, and products $\mathbf{2} \mathbf{b}$ and $\mathbf{4 b}$ were transformed into the corresponding $N$-methoxycarbonyl derivatives, $3 \mathbf{b}(61 \%)$ and $\mathbf{5 b}(35 \%)$, respectively (entry 7$)$.

MX faujasites were superior catalysts in terms of both efficiency and selectivity. At $180{ }^{\circ} \mathrm{C}(Q=1,4 \mathrm{~h})$, the methyl ester $\mathbf{2 b}$ was isolated in a $87 \%$ yield over LiX (entry 8), while compound 3b [methyl( $N$-methoxycarbonyl)-3-indolyl acetate] was obtained in 97 and 98\% yields, in reactions catalyzed by $\mathrm{NaX}$ and $\mathrm{KX}$, respectively (entries 9 and 10). At a lower temperature $\left(160{ }^{\circ} \mathrm{C}\right)$, the esterification of $\mathbf{1 b}$ was the exclusive process observed with $\mathrm{NaX}$ and $\mathrm{KX}$, even at $Q$ ratios of 0.05 0.1 . Isolated yields of $\mathbf{2 b}$ were of 93-96\% (entries 11, 12 and 14) and of $44 \%$ (entry 13). In all cases, side-products $\mathbf{4 b}$ and $\mathbf{5 b}$ were never detected.

Reactions of DMC with indolyl-3-propionic, -3-butyric acids, -3-carboxylic, -2-carboxylic, and -6-carboxylic acids (1c, 1d, 1a, 1e, and 1f, respectively) were investigated under the same conditions used for $\mathbf{1 b}$. Solutions of compounds $\mathbf{1}$ in $\operatorname{DMC}\left(4.5 \times 10^{-2} \mathrm{M}, 30 \mathrm{~mL}\right)$ were set to react at 160 and $180{ }^{\circ} \mathrm{C}$, in the presence of $\mathrm{NaY}$ and $\mathrm{MX}(\mathrm{M}=\mathrm{Na}, \mathrm{Li})$ catalysts [weight ratios $(Q)$ of catalyst : substrate were of 0.1 and 1]. In the case of substrates $\mathbf{1 c}, \mathbf{d}$, products coming from the esterification of the acid function (compounds $\mathbf{2} \mathbf{c}, \mathbf{d}$ ), and from the $N$-methoxycarbonylation of the indolyl $\mathrm{NH}$ group (compounds 3c,d) were observed [Scheme 5, path (a)]. The reactions of DMC with acids $\mathbf{1 a}$, and $\mathbf{1 e}$ and $\mathbf{1 f}$ yielded methyl esters $(\mathbf{2 e}, \mathbf{f})$ along with indole (6) originated by the decarboxylation of reagents [Scheme 5, paths (b) and (c)]. Products were isolated and identified by GC/MS and NMR. The results are reported in Table 3 .

\section{Acids 1c,d}

As in the case of indolyl-3-acetic acid (1b), MX faujasites were more active than $\mathrm{NaY}$. At $180{ }^{\circ} \mathrm{C}(Q=1)$, reactions of acids

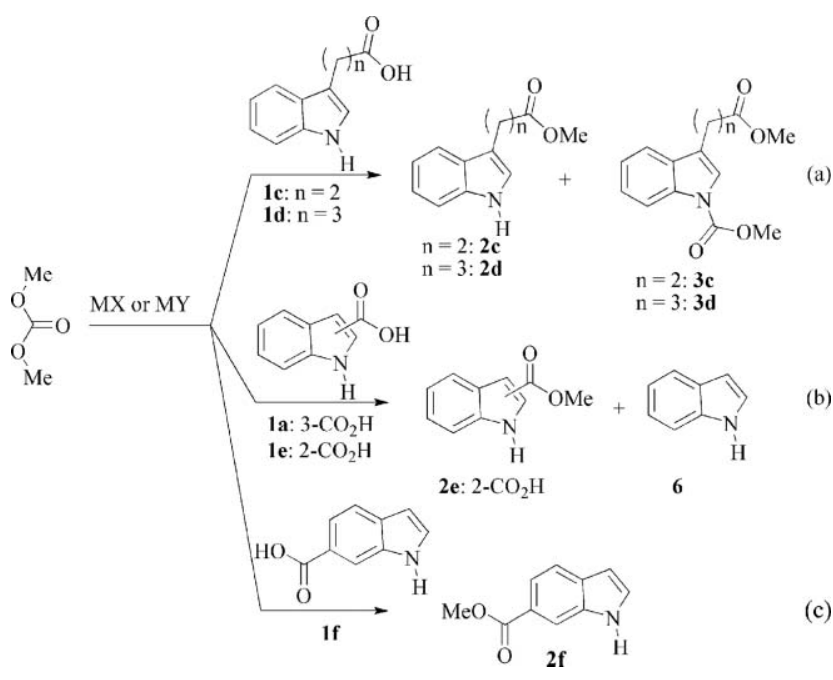

Scheme 5
Table 3 The reaction of DMC with indolyl-3-propionic and indolyl3 -butyric acids (1c and 1d) in the presence of different zeolites

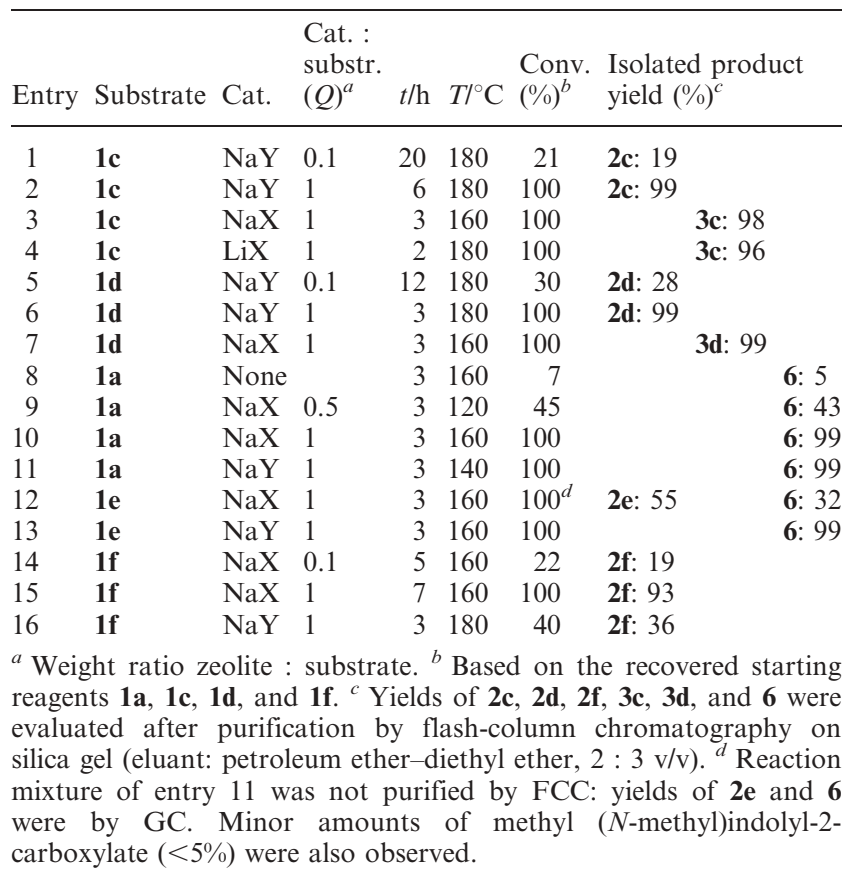

1c,d catalyzed by $\mathrm{NaY}$ gave methyl esters $\mathbf{2 c}$ and $\mathbf{2 d}$ in substantially quantitative yields, after 6 and $3 \mathrm{~h}$, respectively (Table 3, entries 2 and 6). Both processes were also possible with a lower $Q$ ratio of 0.1 (entries 1 and 5).

Instead, in the presence of MX zeolites, simultaneous esterification and $N$-methoxycarbonylation reactions took place to yield compounds $\mathbf{3 c}$ and $\mathbf{3 d}$ as sole products (96$99 \%$, entries 3, 4, and 7). These processes occurred at 160 and $180{ }^{\circ} \mathrm{C}$, over $\mathrm{NaX}$ and $\mathrm{LiX}$, respectively.

Crude esters $\mathbf{2 c , d}$ and carbamate esters $\mathbf{3 c}, \mathbf{d}$ could be recovered in a very high purity (97-98\%), by simple filtration of the zeolite and removal of DMC under vacuum.

It should be noted that, particularly for compounds $\mathbf{3}$, very few synthetic methods are available in the literature, and they are always based on multistep sequences. ${ }^{9}$

\section{Acids 1a, 1e, and 1f}

Indolyl-carboxylic acids (1a, 1e, and 1f) showed quite a different behaviour with respect to $\mathbf{1 b}$-d. Regardless of the reaction conditions (catalyst, temperature, and time), acid 1a, substituted at position 3, gave only the decarboxylation reaction to produce indole $\mathbf{6}$ in a substantially quantitative yield (Table 3, entries 9-11). In this case, a sluggish formation of indole $\left(5 \%, 3 \mathrm{~h}, 160{ }^{\circ} \mathrm{C}\right)$ was observed also without any catalyst (entry 8). In the presence of $\mathrm{NaX}$, acid 1e, substituted at position 2, yielded a mixture of the methyl ester $2 \mathrm{e}(55 \%)$ and indole 6 (32\%) (entry 12), whereas the decarboxylation of 1e was the sole reaction observed over the NaY catalyst (entry 13). Only indolyl-6-carboxylic acid 1f underwent a highly chemoselective esterification process: the reaction was catalyzed by both $\mathrm{NaX}$ and $\mathrm{NaY}$, at 160 and $180{ }^{\circ} \mathrm{C}$, respectively (entries 14-16). The methyl ester $2 \mathbf{f}$ was isolated in up to $93 \%$ yield (entry 15). 
In all cases, faujasite catalysts were easily recyclable: after reactions of acids $\mathbf{1 a}-\mathbf{f}$, they could be separated by filtration and re-activated by a mild thermal treatment $\left(90{ }^{\circ} \mathrm{C} / 0.1 \mathrm{~mm}\right.$, overnight). Both catalytic activity and selectivity were fully restored. For instance, when a re-activated $\mathrm{NaX}$ was used under the conditions of entry 11 of Table 2, the reaction of indolyl-3-acetic acid (1b) with DMC yielded the corresponding methyl ester (2b) in $92 \%$ isolated yield.

\section{Discussion}

\section{Acids 1b-d}

Acid-base properties of MY and MX faujasites affect the results of Tables 2 and 3. In particular, according to the scale proposed by Barthomeuf (Scheme 6), ${ }^{10}$ the more basic MX show better performances than MY. The latter, especially LiY, operates only at $180{ }^{\circ} \mathrm{C}$ : they promote either the competitive reactions of esterification and decarboxylation of $\mathbf{1 b}$, or the esterification of acids $\mathbf{1 c}, \mathbf{d} .^{11}$

At $160{ }^{\circ} \mathrm{C}$ instead, $\mathrm{NaX}$ and $\mathrm{KX}$ faujasites selectively catalyze the formation of esters $\mathbf{2} \mathbf{b}$ and carbamate esters $\mathbf{3 c}, \mathbf{d}$. The same reactions require a higher temperature of $180{ }^{\circ} \mathrm{C}$, with respect to the less basic LiX.

In the case of indolyl-3-acetic acid (1b), MX zeolites are further activated by the temperature: at $180{ }^{\circ} \mathrm{C}, \mathrm{NaX}$ and $\mathrm{KX}$ allow a rapid and quantitative conversion of ester $\mathbf{2 b}$ into $\mathbf{3 b}$. While, under the same conditions, a sluggish and not selective reaction is observed when $\mathrm{NaY}$ is the catalyst (Table 2, entry 6). Shieh et al. reported that the $N$-methoxycarbonylation of 5-bromoindole with DMC also takes place only in the presence of moderate-to-strong organic bases (DMAP and DBU). ${ }^{12}$

\section{Acids 1a, 1e,f}

For indolyl-carboxylic acids, the effect of the catalyst is evident for 1e and, particularly, for 1f: faster esterification reactions and better yields of products $\mathbf{2 e}$ and $\mathbf{2} \mathbf{f}$ are achieved over $\mathrm{NaX}$ faujasite with respect to $\mathrm{NaY}$ (entries 11-15, Table 3). However, the reactivity of compounds 1a, and 1e and 1 also reflects the relative positions of the $\mathrm{NH}$ and $\mathrm{CO}_{2} \mathrm{H}$ groups. The high electron density of positions 2 and, especially, 3 of the pyrrole ring of the indoles ${ }^{13}$ may account for the important, if not exclusive, decarboxylation reaction observed for reagents 1a and 1e. By contrast, this process is totally absent for indolyl-6-carboxylic acid. The lower reactivity of indolyl-3-acetic acid $\mathbf{1 b}$ compared to its homologues 1c and 1d (Tables 2 and 3) can be explained accordingly.

Overall, the surface interactions between reagents and catalysts can be affected by the different acid-base features

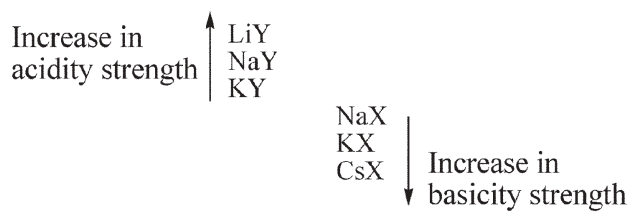

Scheme 6
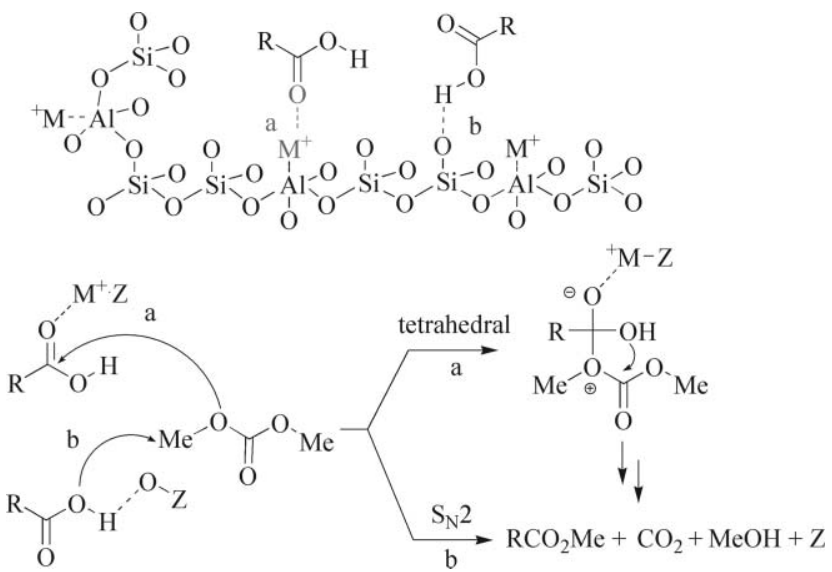

Scheme 7

of MY/MX solids. Scheme 7 describes two plausible modes of adsorption of carboxylic acids over alkali metal exchanged faujasites. $^{14}$

The formation of methyl esters $\mathbf{2 b}, \mathbf{c}$ (Schemes 4 and 5) may proceed according to tetrahedral or $\mathrm{S}_{\mathrm{N}} 2$-type or both mechanisms, which are possibly favored over more basic $\mathrm{X}$ zeolites.

Indole-NH groups of acids $\mathbf{1}$ are also expected to bind to the polar surface of MY/MX faujasites. ${ }^{15}$ Nevertheless, the reactivity of $\mathrm{CO}_{2} \mathrm{H}$ and $\mathrm{NH}$ functionalities is highly discriminated. Not to mention that compounds $\mathbf{1}$ never undergo $N$-methylation reactions which are always observed over conventional basic catalysts (Scheme 3). ${ }^{16,17}$ This fine tuning of the selectivity suggests that the activation of acids $\mathbf{1}$ is a complex phenomenon where both the geometry of adsorption of reagents and the steric requisites of faujasites, can be involved. ${ }^{18}$

\section{Conclusions}

The combination of dimethyl carbonate and Y or X faujasites allows a straightforward and high-yield synthesis of methyl esters $\mathbf{2}$ or methyl carbamate esters $\mathbf{3}$ derived from indolyl acids 1. In particular, alkali metal exchanged $\mathrm{X}$ zeolites are superior catalysts in terms of both efficiency and selectivity. Typical chemoselectivity is up to $99 \%$ at quantitative conversions, a result hitherto not possible with standard basic catalysts (i.e. $\mathrm{K}_{2} \mathrm{CO}_{3}$ ), where only products of simultaneous esterification and $\mathrm{N}$-methylation of acids $\mathbf{1}$ are obtained. Under the explored conditions, the reaction outcome is affected by the acid-base nature of MX/MY zeolites which likely alters the surface interactions between reagents and catalysts.

Although the procedure is rather energy-intensive, multiple green features can be recognized: (i) the non-toxic DMC is used as a reagent/solvent which can be recycled; ${ }^{19}$ (ii) eco-safe solids (faujasites) are catalysts which can be easily separated and recycled; (iii) except for $\mathrm{MeOH}$ and $\mathrm{CO}_{2}$, no organic/ inorganic by-products are observed; and (iv) thanks to the high chemoselectivity, not only derivatization sequences can be avoided, but also purification steps are much simplified. 


\section{Experimental}

Compounds 1 and DMC were ACS grade and were employed without further purification. Zeolites $\mathrm{NaY}$ and $\mathrm{NaX}$ were from Aldrich. Other MY and MX catalysts $(\mathrm{M}=\mathrm{Li}, \mathrm{Na}, \mathrm{K})$ were prepared according to a procedure previously reported by us. ${ }^{2 h}$ Before each reaction, all the faujasites were dehydrated by being heated at $65{ }^{\circ} \mathrm{C}$ under vacuum $(10 \mathrm{~mm} \mathrm{Hg})$ overnight.

MS (EI, $70 \mathrm{eV}$ ) analyses were run using HP5/MS capillary columns (30 m). ${ }^{1} \mathrm{H}$ and ${ }^{13} \mathrm{C}$ NMR spectra were recorded on a $300 \mathrm{MHz}$ spectrometer, using $\mathrm{CDCl}_{3}$ as solvent.

\section{Reactions carried out in autoclave. General procedure}

A stainless-steel autoclave ( $90 \mathrm{~mL}$ of internal volume) was charged with a solution $\left(4.5 \times 10^{-2} \mathrm{M} ; 30 \mathrm{~mL}\right)$ of the chosen acid $(1,1.35 \mathrm{mmol})$, dimethyl carbonate $(0.36 \mathrm{~mol})$ and $\mathrm{MY}$ or $\mathrm{NaX}$ faujasites (catalyst : substrate in a $0.1-1$ weight ratio, see Tables 2 and 3). At room temperature and before the reaction, air was removed by a purging valve with a $\mathrm{N}_{2}$ stream. The autoclave was then heated by an oil-circulating jacket, while the mixture was kept under magnetic stirring throughout the reaction. A thermocouple fixed onto the autoclave head monitored the temperature $\left(160-180{ }^{\circ} \mathrm{C}\right)$. After different time intervals (3-20 h), the autoclave was cooled to rt, purged from $\mathrm{CO}_{2}$ and, finally, opened. The reaction mixture was analysed by GC/MS.

Crude esters $\mathbf{2 b}$ and $\mathbf{2 f}$, and carbamate esters $\mathbf{3 b}-\mathbf{d}$ were isolated in $93-98 \%$ GC-purity by simple filtration of the $\mathrm{NaX}$ catalyst and removal of DMC under vacuum $\left(35^{\circ} \mathrm{C} / 250 \mathrm{~mm}\right)$. Likewise, products $\mathbf{2 c}$ and $\mathbf{2 d}(98 \%$ GC) were obtained from reactions catalyzed by MY zeolites. Products $\mathbf{4 b}$ and $\mathbf{5 b}$ were obtained from the reaction of $\mathbf{1 b}$ with DMC over MY faujasites (Table 2). Reaction mixtures were further purified by FCC on silica gel F60 (eluant: petroleum ether-diethyl ether in $2: 3 \mathrm{v} / \mathrm{v}$ ).

All compounds were characterized by GC/MS and ${ }^{1} \mathrm{H}$ NMR. Spectroscopic data of $\mathbf{2 b - d , ~ 2 f , ~ 3 b , ~} \mathbf{4 b}, \mathbf{5 b}$, and $\mathbf{6}$ were already reported in the literature. ${ }^{9,20-24}$ The structures of new compounds $\mathbf{3 c}$ and $\mathbf{3 d}$ were confirmed also by ${ }^{13} \mathrm{C}$ NMR.

${ }^{1} \mathrm{H}$ NMR spectra were recorded at $300 \mathrm{MHz},{ }^{13} \mathrm{C}$ NMR at $75 \mathrm{MHz}$. Chemical shifts were reported in $\delta$ values downfield from TMS. $\mathrm{CDCl}_{3}$ was used as the solvent.

The structures of esters $\mathbf{2 b}-\mathbf{d}$ and $\mathbf{2 f}$, and of indole $\mathbf{6}$ were confirmed also by comparison to authentic samples. Compound 2e was not isolated: its structure was assigned by GC/MS.

\section{Methyl indolyl-3-acetate 2b}

Mp 42-44 ${ }^{\circ} \mathrm{C}$ (pale yellow solid) [lit. $\left.{ }^{20 a} \mathrm{mp} 47-48{ }^{\circ} \mathrm{C}\right] .{ }^{1} \mathrm{H}$ NMR (300 MHz, $\left.\mathrm{CDCl}_{3}\right) \delta 3.74(\mathrm{~s}, 3 \mathrm{H}), 3.82(\mathrm{~s}, 2 \mathrm{H}), 7.12-7.29$ (m, 3H), 7.34-7.39 (m, 1H), 7.62-7.68 (m, 1H), 8.18 (brs, 1H). MS (EI), $m / z$ (relative int.): $189\left(\mathrm{M}^{+}, 32 \%\right), 131(11), 130\left(\mathrm{M}^{+}\right.$ - $\left.\mathrm{CO}_{2} \mathrm{Me}, 100\right), 103$ (7), 77 (8).

\section{Methyl indolyl-3-propionate $2 \mathrm{c}^{21}$}

Mp 75-76 ${ }^{\circ} \mathrm{C}$ (white solid) [lit. $\left.{ }^{20 b} \mathrm{mp} 79-80{ }^{\circ} \mathrm{C}\right] .{ }^{1} \mathrm{H}$ NMR $(300 \mathrm{MHz}, \mathrm{CDCl} 3) \delta 2.75(\mathrm{t}, 2 \mathrm{H}, J=8.1 \mathrm{~Hz}), 3.14(\mathrm{t}, 2 \mathrm{H}$, $J=7.9 \mathrm{~Hz}), 3.7(\mathrm{~s}, 3 \mathrm{H}), 7.03(\mathrm{~m}, 1 \mathrm{H}), 7.10-7.26(\mathrm{~m}, 2 \mathrm{H})$,
7.35-7.41 (m, 1H), 7.62-7.66 (m, 1H), 8.02 (brs, 1H). MS (EI), $\mathrm{m} / \mathrm{z}$ (relative int.): $203\left(\mathrm{M}^{+}, 18 \%\right), 131$ (11), $130\left(\mathrm{M}^{+}-\right.$ $\left.\mathrm{CH}_{2} \mathrm{CO}_{2} \mathrm{Me}, 100\right), 103$ (4), 77 (6).

\section{Methyl indolyl-3-butyrate $2 \mathrm{~d}^{22}$}

Mp 70-71 ${ }^{\circ} \mathrm{C}$ (colorless solid) [lit. ${ }^{20 c} \mathrm{mp} 70-72{ }^{\circ} \mathrm{C}$ ]. ${ }^{1} \mathrm{H}$ NMR $\left(300 \mathrm{MHz}, \mathrm{CDCl}_{3}\right) \delta 2.06$ (qui, $2 \mathrm{H}, J=7.35 \mathrm{~Hz}$ ), $2.41(\mathrm{t}, 2 \mathrm{H}$, $J=7.54 \mathrm{~Hz}), 2.82(\mathrm{t}, 2 \mathrm{H}, J=7.54 \mathrm{~Hz}), 3.67(\mathrm{~s}, 3 \mathrm{H}), 7.00(\mathrm{~m}$, 1H), 7.08-7.24 (m, $2 \mathrm{H}), 7.33-7.39(\mathrm{~m}, 1 \mathrm{H}), 7.57-7.65(\mathrm{~m}, 1 \mathrm{H})$, 7.98 (brs, 1H). MS (EI), $m / z$ (relative int.): $217\left(\mathrm{M}^{+}, 28 \%\right), 186$ $\left(\mathrm{M}^{+}-\mathrm{OMe}, 9\right), 143\left(\mathrm{M}^{+}-\mathrm{CH}_{2} \mathrm{CO}_{2} \mathrm{Me}-\mathrm{H}, 21\right), 130\left(\mathrm{M}^{+}-\right.$ $\mathrm{CH}_{2} \mathrm{CH}_{2} \mathrm{CO}_{2} \mathrm{Me}$ ), 77 (7).

\section{Methyl indolyl-2-carboxylate, $2 \mathrm{e}^{23}$}

MS (EI), $m / z$ (relative int.): $175\left(\mathrm{M}^{+}, 65 \%\right), 144\left(\mathrm{M}^{+}-\mathrm{OMe}\right.$, 21), 143 (100), $116\left(\mathrm{M}^{+}-\mathrm{CO}_{2} \mathrm{Me}, 12\right), 115$ (53), 89 (28).

\section{Methyl indolyl-6-carboxylate $2 \mathrm{f}$}

Mp 74-76 ${ }^{\circ} \mathrm{C}$ (pale yellow solid) $\left[\right.$ lit. $\left.{ }^{24} \mathrm{mp} 71-72{ }^{\circ} \mathrm{C}\right]{ }^{1} \mathrm{H}$ NMR $\left(300 \mathrm{MHz}, \mathrm{CDCl}_{3}\right) \delta 3.93(\mathrm{~s}, 3 \mathrm{H}), 6.61(\mathrm{~m}, 1 \mathrm{H}), 7.38(\mathrm{~m}, 1 \mathrm{H})$, $7.66(\mathrm{~d}, 1 \mathrm{H}, J=8.3 \mathrm{~Hz}), 7.82\left(\mathrm{dd}, 1 \mathrm{H}, J_{1}=8.5 \mathrm{~Hz}, J_{2}=1.5 \mathrm{~Hz}\right)$, 8.17 (m, $1 \mathrm{H}), 8.45$ (brs, $1 \mathrm{H})$. MS (EI), $m / z$ (relative int.): 175 $\left(\mathrm{M}^{+}, 73 \%\right), 145(11), 144\left(\mathrm{M}^{+}-\mathrm{OMe}, 100\right), 116\left(\mathrm{M}^{+}-\right.$ $\left.\mathrm{CO}_{2} \mathrm{Me}, 50\right), 89$ (18).

\section{Methyl ( $N$-methoxycarbonyl)indolyl-3 acetate 3b}

Mp 30-32 ${ }^{\circ} \mathrm{C}$ (white solid) [lit. ${ }^{9} \mathrm{mp} 34-35{ }^{\circ} \mathrm{C}$ ]. ${ }^{1} \mathrm{H}$ NMR $\left(300 \mathrm{MHz}, \mathrm{CDCl}_{3}\right) \delta 3.72(\mathrm{~s}, 5 \mathrm{H}), 4.03(\mathrm{~s}, 3 \mathrm{H}), 7.24-7.40(\mathrm{~m}$, 2H), 7.51-7.56 (m, 1H), $7.60(\mathrm{~s}, 1 \mathrm{H}), 8.17(\mathrm{~d}, 1 \mathrm{H}, J=8.1 \mathrm{~Hz})$. MS (EI), $m / z$ (relative int.): $247\left(\mathrm{M}^{+}, 56 \%\right), 189$ (13), 188 $\left(\mathrm{M}^{+}-\mathrm{CO}_{2} \mathrm{Me}, 100\right), 143\left(\mathrm{M}^{+}-\mathrm{CH}_{2} \mathrm{CO}_{2} \mathrm{Me}, 40\right), 129\left[\mathrm{M}^{+}-\right.$ $\left.\left(\mathrm{CO}_{2} \mathrm{Me}\right)_{2}, 19\right], 128$ (13), 102 (20), 76 (10).

\section{3-Methylindole 4b}

Mp 96-98 ${ }^{\circ} \mathrm{C}$ (white solid) [lit. $\left.{ }^{25} \mathrm{mp} 98-98.5{ }^{\circ} \mathrm{C}\right] .{ }^{1} \mathrm{H}$ NMR $\left(300 \mathrm{MHz}, \mathrm{CDCl}_{3}\right) \delta 2.35(\mathrm{~d}, 3 \mathrm{H}, J=1.1 \mathrm{~Hz}), 6.97(\mathrm{~m}, 1 \mathrm{H})$, 7.09-7.24 (m, 2H), 7.32-7.38 (m, 1H), 7.57-7.63 (m, 1H), 7.87 (brs, $1 \mathrm{H})$. MS (EI), $m / z$ (relative int.): $131\left(\mathrm{M}^{+}, 58 \%\right), 130$ $\left(\mathrm{M}^{+}-\mathrm{H}, 100\right), 102$ (6), 77 (12).

\section{(N-Methoxycarbonyl)-3-methylindole 5b}

Viscous oil [lit. ${ }^{26} \mathrm{bp} 101-102{ }^{\circ} \mathrm{C} / 0.5$ torr]. ${ }^{1} \mathrm{H}$ NMR $(300 \mathrm{MHz}$, $\left.\mathrm{CDCl}_{3}\right) \delta 2.19(\mathrm{~d}, 3 \mathrm{H}, J=1.1 \mathrm{~Hz}), 3.93(\mathrm{~s}, 3 \mathrm{H}), 7.15-7.32(\mathrm{~m}$, $3 \mathrm{H}), 7.40-7.45(\mathrm{~m}, 1 \mathrm{H}), 8.00(\mathrm{~m}, 1 \mathrm{H})$. MS (EI), $\mathrm{m} / z$ (relative int.): 190 (12), $189\left(\mathrm{M}^{+}, 100 \%\right), 144(82), 130\left(\mathrm{M}^{+}-\mathrm{CO}_{2} \mathrm{Me}\right.$, 48), 103 (16), 77 (24).

\section{Methyl ( $N$-methoxycarbonyl)-3-indolyl propionate 3c}

Mp 40-43 ${ }^{\circ} \mathrm{C}$ (white solid); ${ }^{1} \mathrm{H}$ NMR ( $\left.300 \mathrm{MHz}, \mathrm{CDCl}_{3}\right) \delta 2.72$ (t, $2 \mathrm{H}, J=7.9 \mathrm{~Hz}), 3.01(\mathrm{t}, 2 \mathrm{H}, J=8.0 \mathrm{~Hz}), 3.69(\mathrm{~s}, 3 \mathrm{H}), 4.02$ (s, 3H), 7.23-7.38 (m, 2H), $7.40(\mathrm{~s}, 1 \mathrm{H}), 7.51-7.56(\mathrm{~m}, 1 \mathrm{H})$, $8.16(\mathrm{~d}, 1 \mathrm{H}, J=8.3 \mathrm{~Hz}) ;{ }^{13} \mathrm{C}$ NMR $\left(75 \mathrm{MHz}, \mathrm{CDCl}_{3}\right) \delta 20.18$, $33.46,51.62,53.58,115.12,118.75,120.18,122.03,122.70$, 124.62, 130.12, 135.46, 151.30, 173.19. MS (EI), $\mathrm{m} / \mathrm{z}$ (relative int.): $261\left(\mathrm{M}^{+}, 44 \%\right), 201\left(\mathrm{M}^{+}-\mathrm{CO}_{2} \mathrm{Me}-\mathrm{H}, 11\right), 188$ 
$\left(\mathrm{M}^{+}-\mathrm{CH}_{2} \mathrm{CO}_{2} \mathrm{Me}, 100\right), 144$ (36), $143\left[\mathrm{M}^{+}-\left(\mathrm{CO}_{2} \mathrm{Me}\right)_{2}, 20\right]$, 129 (13), 115 (22), 59 (14).

\section{Methyl ( $N$-methoxycarbonyl)-3-indolyl butyrate 3d}

Mp 63-65 ${ }^{\circ} \mathrm{C}$ (white solid); ${ }^{1} \mathrm{H}$ NMR (300 MHz, $\left.\mathrm{CDCl}_{3}\right) \delta 2.04$ (qui, $2 \mathrm{H}, J=7.4 \mathrm{~Hz}), 2.40(\mathrm{t}, 2 \mathrm{H}, J=7.3 \mathrm{~Hz}), 2.73\left(\mathrm{td}, 2 \mathrm{H}, J_{1}=\right.$ $\left.7.5 \mathrm{~Hz}, J_{2}=1.1 \mathrm{~Hz}\right), 3.67(\mathrm{~s}, 3 \mathrm{H}), 4.02(\mathrm{~s}, 3 \mathrm{H}), 7.22-7.37(\mathrm{~m}$, $2 \mathrm{H}), 7.39(\mathrm{~m}, 1 \mathrm{H}), 7.51-7.56(\mathrm{~m}, 1 \mathrm{H}), 8.16(\mathrm{~d}, 1 \mathrm{H}, J=7.9 \mathrm{~Hz})$; ${ }^{13} \mathrm{C}$ NMR $\left(75 \mathrm{MHz}, \mathrm{CDCl}_{3}\right) \delta 24.17,24.21,33.45,51.49$, $53.59,115.11,118.98,120.92,122.11,122.67,124.55,130.42$, 135.59, 151.39, 173.78. MS (EI), $m / z$ (relative int.): 276 (14), $275\left(\mathrm{M}^{+}, 81 \%\right), 244\left(\mathrm{M}^{+}-\mathrm{OMe}, 16\right), 202(17), 201\left(\mathrm{M}^{+}-\right.$ $\left.\mathrm{CO}_{2} \mathrm{Me}-\mathrm{Me}, 78\right), 188$ (100), 156 (15), 144 (43), 143 (18), 129 (20), 115 (15).

\section{Indole 6}

Mp 47-49 ${ }^{\circ} \mathrm{C}$ (yellow solid) [lit. $\left.{ }^{27} \mathrm{mp} 52{ }^{\circ} \mathrm{C}\right]$.

\section{Acknowledgements}

MIUR (Italian Ministry of University and Research) and EU 6th-FP (solvsafe project: www.solvsafe.com) are gratefully acknowledged for financial support.

\section{References}

1 (a) A.-A. G. Shaik and S. Sivaram, Chem. Rev., 1996, 96, 951-976; (b) P. Tundo and M. Selva, Acc. Chem. Res., 2002, 35, 706-716.

2 (a) P. Tundo, Continuous Flow Methods in Organic Synthesis, Horwood, Chichester, UK, 1991; (b) M. Aresta and E. Quaranta, Tetrahedron, 1991, 47, 9489-9502; (c) M. Selva, C. A. Marques and P. Tundo, J. Chem. Soc., Perkin Trans. 1, 1994, 1323-1328; (d) Z.-H. Fu and Y. Ono, J. Catal., 1994, 145, 166-170; (e) Y. Ono, Appl. Catal., 1997, 155, 136; ( $f$ ) M. Selva, A. Bomben and P. Tundo, J. Chem. Soc., Perkin Trans. 1, 1997, 1041-1045; (g) M. Selva, P. Tundo and A. Perosa, J. Org. Chem., 2001, 66, 677-680; (h) D. Delledonne, F. Rivetti and U. Romano, Appl. Catal., A, 2001, 221, 241-251; (i) M. Selva, P. Tundo and A. Perosa, J. Org. Chem., 2002, 67, 9238-9247; (j) M. Selva, P. Tundo, A. Perosa and S. Memoli, J. Org. Chem., 2002, 67, 1071-1077; $(k)$ M. Selva, P. Tundo, A. Perosa and F. Dall'Acqua, J. Org. Chem., 2005, 70, 2771-2777.

3 (a) M. Selva, P. Tundo and A. Perosa, J. Org. Chem., 2003, 68, 7374-7378; (b) M. Selva, P. Tundo and T. Foccardi, J. Org. Chem., 2005, 70, 2476-2485.

4 M. Selva and P. Tundo, J. Org. Chem., 2006, 71, 1464-1470.

5 (a) D. W. Armstrong, Y.-S. Liu, L. He and K. H. Ekborg-Ott, J. Agric. Food Chem., 2002, 50, 473-476; (b) G. R. Humphrey and J. T. Kuethe, Chem. Rev., 2006, 106, 2875-2911.

6 X. Jiang, A. Tiwari, M. Thompson, Z. Chen, T. P. Cleary and T. B. K. Lee, Org. Process Res. Dev., 2001, 5, 604-608.

7 M. Onaka, K. Ishikawa and Y. Izumi, Chem. Lett., 1982, 1783.

8 In ref. 6, a decarboxylation process was described for the reaction of indolyl-3-carboxylic acid (1a) with DMC, catalyzed by $\mathrm{K}_{2} \mathrm{CO}_{3}$.

9 M.-L. Bennasar, E. Zulaica, A. Ramirez and J. Bosch, J. Org. Chem., 1996, 61, 1239-1251.

10 (a) D. Barthomeuf, J. Phys. Chem., 1984, 88, 42-45; (b) B. Su and D. Barthomeuf, Stud. Surf. Sci. Catal., 1995, 94, 598. The rationale of Scheme 6 is based on: (i) the charge-to-mass ratio of metal cations ( $\mathrm{Li}>\mathrm{Na}>\mathrm{K}>\mathrm{Cs}$; acid sites); and (ii) the $\mathrm{Si} / \mathrm{Al}$ ratio of the aluminosilicate framework (1-1.5 and $1.5-3$, for MX and MY, respectively). This ratio directly affects the strength of basic sites identified with the oxygen atoms of the aluminosilicate framework.

11 Likely, in the reactions of indolyl-3-acetic acid (Table 2), the second decarboxylated product (5b) comes from the $\mathrm{N}$-methoxycarbonylation reaction of compound $\mathbf{3 b}$ with DMC.

12 W.-C. Shieh, S. Dell, A. Bach, O. Repic and T. J. Blacklock, J. Org. Chem., 2003, 68, 1954-1957.

13 J. March, Advanced Organic Chemistry, Reaction, Mechanisms, and Structure, Wiley, New York, 4th edn, 1992, ch. 11, pp. 514-516.

14 Spectroscopic investigations demonstrate that, upon adsorption over both MY and MX catalysts, both DMC and several nucleophiles (phenols, thiophenols, and amines) are activated via either interactions with acidic metal cations $\left(\mathrm{M}^{+}=\mathrm{Li}, \mathrm{Na}, \mathrm{K}\right)$, and $\mathrm{H}$-bonds with basic oxygen atoms of the aluminosilicate structure of faujasites. See: (a) T. Beutel, J. Chem. Soc., Faraday Trans., 1998, 94, 985; (b) F. Bonino, A. Damin, S. Bordiga, M. Selva, P. Tundo and A. Zecchina, Angew. Chem., Int. Ed., 2005, 44, 4774-4777; (c) M. Czjzek, T. Vogt and H. Fuess, Zeolites, 1991, 11, 832; (d) T. Beutel, M.-J. Peltre and B. L. Su, Colloids Surf., A, 2001, 187, 319-325; (e) Z.-H. Fu and Y. Ono, Catal. Lett., 1993, 21, 43-47. To our knowledge, such data are not available for carboxylic acids, and particularly, for indolyl acids. Scheme 7 illustrates a reasonable hypothesis.

15 Compounds 1 are also weak bases; see: B. Andonovski, I. Spirevska and A. Nikolovski, Croat. Chim. Acta, 1996, 69, 1201-1213.

16 Shieh et al. (see ref. 12) observed that also in the reaction of 5-bromoindole with DMC, the nature of the basic catalyst drives the overall selectivity: in particular, the increase of the basic strength (DBU > DMAP $>$ DABCO), favors the $N$-methoxycarbonylation reaction $v s$. the competitive $N$-methylation process.

17 In the presence of $\mathrm{K}_{2} \mathrm{CO}_{3}$ or TBAB $\left(n-\mathrm{Bu}_{4} \mathrm{NBr}\right)$, also pyrrole and benzimidazole react with $\mathrm{DMC}$ to produce the corresponding $N$-methyl derivatives; see: M. Lissel, S. Schmidt and B. Neumann, Synthesis, 1986, 382-382; S. Ouk, S. Thiebaud, E. Borredon and B. Chabaud, Synth. Commun., 2005, 35, 3021-3026.

18 In particular, supercages of the 3D-structure of MY and MX faujasites may induce a shape selectivity effect. See ref. 1b, 3, 4, 12, 13.

19 DMC can be recovered quantitatively by distillation at atmospheric pressure $\left(90{ }^{\circ} \mathrm{C}\right)$. However, both methylation and methoxycarbonylation reactions mediated by dimethyl carbonate produce $\mathrm{MeOH}$ (as a co-product) which forms a minimum boiling point azeotrope $\left(70: 30 ; 63{ }^{\circ} \mathrm{C}, 1 \mathrm{~atm}\right)$ with $\mathrm{DMC}$ itself. In the current practice, the azeotrope is separated by distillation under pressure $\left(140{ }^{\circ} \mathrm{C}\right.$, $10 \mathrm{~atm}$; see: (a) J. F. Knifton and R. G. Duranleau, J. Mol. Catal., 1991, 67, 389-399; (b) M. Fuming, P. Zhi and L. Guangxing, Org. Process Res. Dev., 2004, 8, 372-375).

20 (a) Compound 2b: J. A. Nieman, J. E. Coleman, D. J. Fallace, E. Piers, L. Y. Lim, M. Roberge and R. J. Andersen, J. Nat. Prod., 2003, 66, 183-199; (b) compound 2c: Z. Iqbal, A. H. Jackson and K. R. Nagaraja Rao, Tetrahedron Lett., 1988, 29, 2577-2580; (c) compound 2d: G. Dornyei, M. Incze, M. Kajtar-Peredy and C. Szantay, Collect. Czech. Chem. Commun., 2002, 67, 1669-1680.

21 D. H. R. Barton, G. Bringmann and W. B. Motherwell, Synthesis, 1980, 68-70.

22 J. Perregaard, E. K. Moltzen, E. Meier and C. Sanchez, J. Med. Chem., 1995, 38, 1998-2008.

23 J. D. Freed, D. J. Hart and N. A. Magomedov, J. Org. Chem., 2001, 66, 839-852.

24 F. J. Brown, L. A. Cronk, D. Aharony and D. W. Snyder, J. Med. Chem., 1992, 35, 2419-2439.

25 Y. Tsuji, S. Kotachi, K.-T. Huh and Y. Watanabe, J. Org. Chem., 1990, 55, 580-584.

26 E. Wenkert, M. E. Alonso, H. E. Gottlieb and E. L. Sanchez, J. Org. Chem., 1977, 42, 3945-3949.

27 Dictionary of Organic Compounds, ed. John Buckingham, Chapman and Hall, New York, 5th edn, 1982, vol. 3, p. 3305. 